\title{
Brain Stimulation Techniques in the Treatment of Obsessive-Compulsive Disorder: Current and Future Directions
}

\author{
By Bernardo Dell'Osso, MD, Alfredo Carlo Altamura, MD, \\ Andrea Allen, PhD, and Eric Hollander, MD
}

\begin{abstract}
Needs Assessment
In the last decade, brain stimulation approaches to neuropsychiatric disorders have been increasingly investigated and are currently defining a "third way" of treatment besides the traditional ones, pharmacologic therapy and psychotherapy. Although some of these techniques are well-established treatments for specific conditions (ie, electroconvulsive therapy for severe depression or deep brain stimulation and transcranial magnetic stimulation in motor disorders) their efficacy in severe or treatment-resistant obsessive-compulsive disorder is still under investigation. Nevertheless, they represent a potential, helpful approach in this highly debilitating condition not only amongst the therapeutic approaches to obsessive-compulsive disorder but also as research means able to elucidate the specific dysfunctional neurocircuits underlying the clinical symptomatology.
\end{abstract}

\section{Learning Objectives}

At the end of this activity, the participant should be able to:

- Differentiate the specific techniques of brain stimulation investigated in the treatment of obsessive-compulsive disorder (OCD) in terms of efficacy, invasiveness, tolerability, and side effects.

- Understand the main hypotheses through which these techniques might modify the dysfunctional circuits of OCD.

- Understand the potential of these techniques in the field of treatment-resistant OCD, on one hand, and their current investigational state that requires further controlled clinical trials, on the other hand.

\section{Target Audience Neurologists and psychiatrists}

\section{Accreditation Statement}

Mount Sinai School of Medicine is accredited by the Accreditation Council for Continuing Medical Education to provide Continuing Medical Education for physicians.

Mount Sinai School of Medicine designates this educational activity for a maximum of 3.0 Category 1 credit(s) toward the AMA Physician's Recognition Award. Each physician should claim only those credits that he/she actually spent in the educational activity.

It is the policy of Mount Sinai School of Medicine to ensure fair balance, independence, objectivity and scientific rigor in all its sponsored activities. All faculty participating in sponsored activities are expected to disclose to the audience any real or apparent discussion of unlabeled or investigational use of any commercial product or device not yet approved in the United States.

This activity has been peer-reviewed and approved by Eric Hollander, MD, professor of psychiatry, Mount Sinai School of Medicine. Review Date: November 1, 2005.

\section{To Receive Credit for This Activity}

Read this article, and the two CME-designated accompanying articles, reflect on the information presented, and then complete the CME quiz found on pages 984 and 985 . To obtain credits, you should score $70 \%$ or better. Termination date: December 31, 2007. The estimated time to complete this activity is 3 hours.

\begin{abstract}
Recent studies on the epidemiology of obsessive-compulsive disorder (OCD) estimate 50 million patients suffer from OCD worldwide, thus making it a global problem. The treatment of OCD has changed substan-
\end{abstract}

tially over the last 2 decades following the introduction of selective serotonin reuptake inhibitors, which provide symptom improvement in 60\% of patients. However, some patients remain resistant to the standard pharmacologic and behavioral treatments. Although some

Dr. Dell'Osso is postdoctoral research fellow in the Department of Psychiatry, Compulsive, Impulsive and Anxiety Disorders Program, at Mount Sinai School of Medicine (MSSM) in New York City, and research fellow in the Department of Clinical Sciences at the Hospital Luigi Sacco at the University of Milan in Italy. Dr. Altamura is professor of psychiatry in the Department of Clinical Sciences at Hospital Luigi Sacco at the University of Milan. Dr. Allen is assistant professor in the Department of Psychiatry, Compulsive, Impulsive and Anxiety Disorders Program at MSSM. Dr. Hollander is professor of psychiatry in the Department of Psychiatry at MSSM, where he is director of the Seaver and New York Autism Center of Excellence, director of Clinical Psychopharmacology, and director of the Compulsive, Impulsive and Anxiety Disorders Program.

Disclosure: Drs. Dell'Osso, Allen, and Altamura do not have any affiliation or financial interest in any organization that might pose a conflict of interest. Dr. Hollander is on the advisory boards of Abbott, Ortho-McNeil, and Solvay; and has received grant support from Abbott, the National Institute of Drug Addiction, the National Institute of Mental Health, the National Institute of Neurological Diseases and Stroke, Ortho-McNeil, Pfizer, Solvay, UCB Pharma, and Wyeth.

This article was submitted on August 27, 2005, and accepted on November 1, 2005.

Please direct all correspondence to: Bernardo Dell'Osso, MD, Department of Psychiatry, Mount Sinai School of Medicine, One Gustave L. Levy Place, New York, NY 10029; Tel: 212-241-3623, Fax: 212-987-4031; E-mail: bernardo.dellosso@mssm.edu. 
treatment-resistant patients respond to pharmacologic augmentations, others do not, and there is evidence that some of the most severe cases benefit from treatment with neurosurgical interventions. Besides pharmacologic, behavioral, and neurosurgical approaches, different brain stimulation methods-transcranial magnetic stimulation, deep brain stimulation, and electroconvulsive therapy-have been investigated in treatmentresistant patients with OCD. However, available data about the use of these techniques in OCD treatment are quite limited in terms of sample size and study design, given the difficulty in conducting standard blinded trials for these procedures. In addition, none of the mentioned treatments have received Food and Drug Administration approval for the treatment of OCD. Nevertheless, promising findings regarding efficacy, tolerability, and non-invasiveness and/or reversibility of these techniques have increased interest in investigating their use in treatment-resistant OCD.

CNS Spectr. 2005;10(12):966-79,983

\section{INTRODUCTION}

\section{Treatment-Resistant Obsessive-Compulsive Disorder}

Obsessive-compulsive disorder (OCD) is a highly debilitating condition with a lifetime prevalence of $2 \%$ to $3 \%,{ }^{1,2}$ more than twice that of schizophrenia, and is characterized by intrusive, troubling thoughts and/or repetitive, compulsive behaviors or mental rituals. ${ }^{3}$ The economic and social burden of OCD is difficult to quantify, but published data estimate $\$ 8$ billion in the United States annually. ${ }^{4}$ Although the introduction of selective serotonin reuptake inhibitors (SSRIs) has substantially improved the treatment and prognosis of OCD, a notable percentage of patients, ranging from $40 \%$ to $60 \%$, do not respond to SSRI treatment. ${ }^{5}$ In addition, it is noteworthy that the response criterion in clinical trials is generally set as a $25 \%$ to $35 \%$ decrease in OCD symptoms on the Yale-Brown Obsessive Compulsive Scale (YBOCS) ${ }^{6,7}$ It seems appropriate to classify patients with such a reduction as partial responders ${ }^{8}$ and to institute additional treatment.

Specific criteria used to diagnose treatment resistance as well as eligibility for surgical treatments in OCD patients have been published elsewhere. ${ }^{8-10}$ Treatment-resistant OCD represents an ongoing challenge for clinicians and researchers, and over the last decade, different forms of treatment have been investigated, including pharmacologic augmentation strategies (ie, serotonergic, dopaminergic), psychotherapeutic augmentation and brain stimulation.

\section{BRAIN STIMULATION METHODS: BACKGROUND AND DESCRIPTION}

Over the past 10 years, increasing attention has been paid to the possible efficacy of brain stimulation techniques in treatment-resistant neuropsychiatric conditions, such as OCD and major depression. One explanation for the efficacy of these techniques is the possibility that stimulating focal regions of the brain (cortical and subcortical structures) with electrical currents, either directly or indirectly, affects higher cognitive processes and mood systems. ${ }^{11}$ The most widely used of these techniques is electroconvulsive therapy (ECT), which was introduced in psychiatry $>70$ years ago and still represents one of the most effective treatments for severe, treatment-resistant depression. However, it is not a widely accepted technique for treating OCD. Since the efficacy in OCD has not been as clearly demonstrated as in depression, the risks of the procedure and of general anesthesia are not as clearly outweighed by the benefits.

Newer means of electrically stimulating the brain, including transcranial magnetic stimulation (TMS), deep brain stimulation (DBS), magnetic seizure therapy (MST), and vagus nerve stimulation have been developed. One potential advantage of all these different techniques over ECT is that they are able to stimulate more focal regions of the brain.

\section{Transcranial Magnetic Stimulation and Repetitive Transcranial Magnetic Stimulation}

Bickford and colleagues ${ }^{12}$ were the first to extend the field of TMS research to neuropsychiatric conditions. They described temporary mood elevation in several healthy volunteers receiving single-pulse stimulations to the motor cortex. Since then a growing number of studies ${ }^{13}$ have investigated the potential efficacy of TMS in a variety of neuropsychiatric disorders.

TMS is a non-invasive technique that delivers magnetic pulses to the cortex by means of a handheld stimulating coil applied directly to the head. Unlike ECT, magnetic fields pass through the skull and the scalp without the impedance encountered by direct application of electricity. ${ }^{14}$ This means less electricity is delivered to the brain in TMS than in ECT, and allows TMS to stimulate more focal regions of the cortex with fewer side effects. When delivered in trains of pulses, as is usual in clinical practice, TMS is known as repetitive transcranial magnetic stimula- 
tion (rTMS). TMS protocols are generally divided into two types of procedures according to the frequency used: low-frequency TMS $(<1 \mathrm{~Hz})$ and highfrequency TMS $(\leq 20 \mathrm{~Hz})$. Depending on stimulation parameters (frequency, rate, and duration), repetitive stimuli to specific cortical regions can either decrease or enhance the excitability of the affected brain structures (ie, cerebral cortex ${ }^{15-17}$ ) and modify regional cerebral blood flow. ${ }^{18,19}$

\section{Deep Brain Stimulation and Neurosurgery}

DBS is a surgical procedure consisting of the implanting of electrodes that are used to stimulate brain regions directly. Recently, this technique was approved by the Food and Drug Administration for the treatment of intractable motor disorders (tremor ${ }^{20-22}$ and Parkinson's disease ${ }^{23}$ ). The stimulating leads are connected via an extension wire to pulse generators typically placed in the chest (Figure). The precise anatomical localization of the electrodes is achieved with stereotactic imaging via magnetic resonance imaging and computerized tomography. ${ }^{24}$ Implantation of the brain lead is not intended to damage brain tissue, and the stimulation itself can be modified or discontinued if side effects occur. In addition, the procedure is reversible since the devices themselves can be removed.

At high frequencies $(>100 \mathrm{~Hz})$, DBS inhibits neuronal transmission and actions, such as depolarization blockade, synaptic fatigue, or neural jamming, which have been proposed to explain its effect. ${ }^{25}$ Essentially, DBS shows a blocking effect on the stimulated area and mimics the effect of tissue lesioning. ${ }^{26,27}$ However, the reversibility of the intervention results in a lower rate of side effects than lesioning with traditional neurosurgical procedures (ie, thermocoagulation). ${ }^{19}$

\section{Electroconvulsive Therapy and Magnetic Seizure Therapy}

ECT is a well-established treatment for severe depression. ${ }^{28}$ In the last decades, ECT has undergone various revisions improving its safety profile due to the use of general anesthesia, refinements in electrical parameters, introduction of unilateral and bifrontal electrode placement, and better control of electrical dosage relative to the threshold for induction of seizure. Nevertheless, the clinical efficacy of ECT in OCD is still unproven. Published data-mostly case-report series-have shown mixed results (Table 1) ${ }^{29-34}$ and it may be that ECT reduces OCD by treating mental conditions comorbid with OCD (ie, schizophrenia, ${ }^{35}$ depression, ${ }^{36}$ Tourette's syndrome ${ }^{37}$ ) rather than directly reducing OCD. A recent evolution of ECT is MST, a form of convulsive therapy in which a magnetic stimulus ${ }^{38,39}$ replaces the electrical stimulus used in ECT. The use of a magnetic stimulus rather than an electrical one to induce the seizure allows more precision in focus on the site and the extent of stimulation than is possible with traditional ECT, ${ }^{39}$ given that magnetic fields pass through tissue without the impedence encountered by direct application of electricity. MST, therefore, should have better tolerability than ECT and, specifically, should have fewer cognitive side effects. However, MST is still an investigational treatment and has not yet been tested in OCD patients.

\section{CLINICAL STUDIES IN OBSESSIVE-COM- PULSIVE DISORDER PATIENTS}

\section{Transcranial Magnetic Stimulation Studies in Obsessive-Compulsive Disorder}

Four trials of rTMS have been published to date (Table 2)..$^{40-43}$ The findings are inconsistent perhaps because the studies differed in terms of study design, stimulation sites, treatment duration, and stimulation parameters.

Greenberg and colleagues ${ }^{42}$ randomized 12 patients with OCD (mean Y-BOCS: 19.8 \pm 9.7 ; six patients

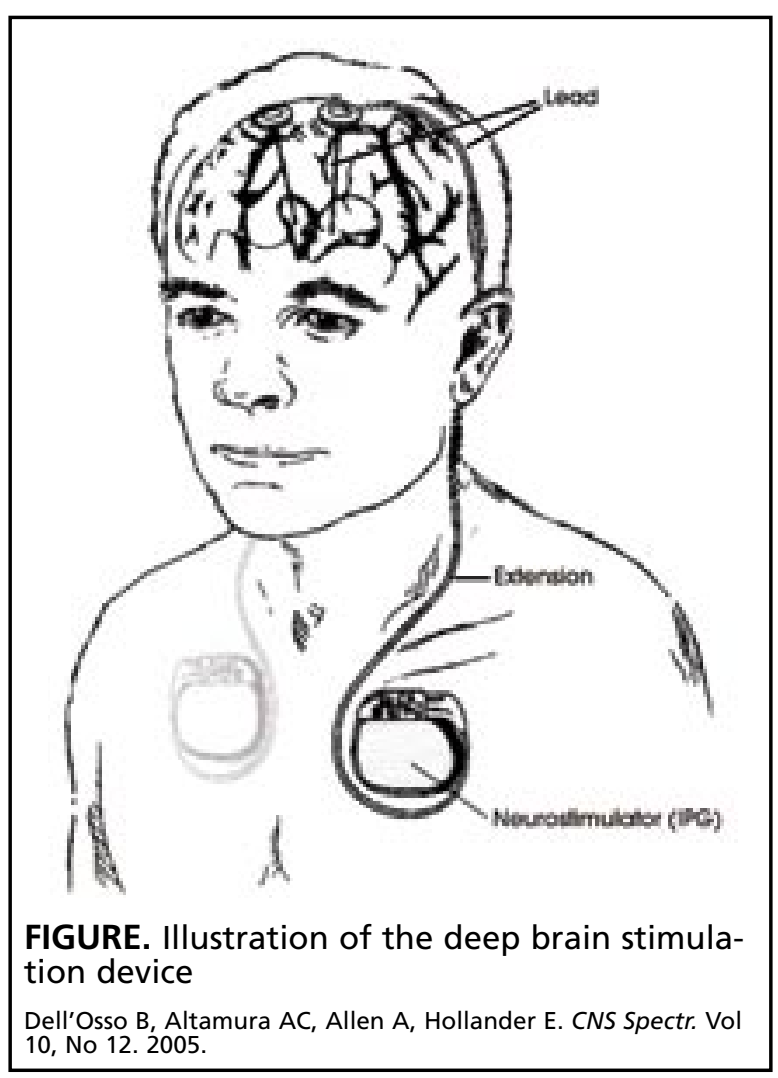


with past or current major depression) into a singleblind trial (patients and raters were blind to the condition but the treating clinician was not). Patients were treated with 1 session of active right-side, active left-side, or sham (occipital position) TMS (frequency: $20 \mathrm{~Hz}$; intensity $80 \%$; 2 seconds/minute, total time: 20 minutes; 8 -shaped coil). Based on previous reports of prefrontal hypermetabolism or hyperperfusion in patients with $\mathrm{OCD},{ }^{44}$ Greenberg and colleagues ${ }^{42}$ believed that the application of a highfrequency rTMS to prefrontal cortex would have transiently interrupted OCD symptoms. Evaluations were made at three time points: during the stimulation, 30-minutes, and 8-hours posttreatment. Compulsive urges decreased significantly from baseline (modified National Institute of Mental Health self-rating scale) after right lateral prefrontal rTMS (during stimulation and 30 minutes, both $P<.01$, and 8 hours after stimulation, $P<.02$ ), but not after left rTMS and not at all in response to occipital rTMS. Obsessive thoughts did not change significantly after any stimulation. There was a modest increase in positive mood after right prefrontal rTMS, while left and occipital stimulation did not affect mood. The main finding was that right prefrontal rTMS had modest acute effects on compulsions whereas effects of left lateral prefrontal and occipital stimulation were transient and nonsignificant. Obsessions appeared unaffected by rTMS. Treatment was well-tolerated, with two patients reporting mild headache after stimulation. Methodological limitations included the duration of the treatment, the lack of Y-BOCS outcome measures, and the small sample.

Alonso and colleagues ${ }^{40}$ found no advantages for 18 OCD patients randomized to either low-frequency right rTMS (1 Hz; intensity: 110\%; time: 20 minutes; circular coil; $n=10)$ or sham stimulation $(n=8)$ in a 6 -week trial ( 3 sessions/week). Notwithstanding the double-blind design of the study, negative findings may be related to type II error, since a minimum of 27 subjects in each treatment condition would have been necessary to reach a power of .80 . No withdrawals were reported throughout the trial and side effects, which consisted of headache and cognitive difficulties, were modest and transient.

Sachdev and colleagues ${ }^{41}$ randomized 12 treatment-resistant OCD patients (a mean number of 5.2 anti-obsessional treatments and 0.8 trials of behavioral therapy had been previously attempted) to a 10 session, single-blind, 2-week trial of active right-side or left-side TMS (10 Hz; intensity: 110\%; 30 trains of 5 seconds each, 25 seconds between trains; time: 15 minutes; 8-shaped coil). Ten subjects were taking medication (benzodiazepines, antidepressants, or anti- psychotics) and had been maintained on a constant dose for 8 weeks prior to and during the period of the study. Evaluations after 2 weeks of stimulation and 1 month after the completion of the treatment showed significant reduction in obsessions and compulsions in both groups with no significant difference between right and left stimulation on the overall Y-BOCS score. Four patients $(33 \%$, two receiving left TMS and two receiving right TMS) had a clinically significant improvement (Y-BOCS reduction $>40 \%$ ); one patient relapsed but responded somewhat to repeated treatment. The authors suggested that rTMS may be beneficial in the acute treatment of treatmentresistant OCD with an equal proportion of patients benefiting from right- and left-sided stimulation. No withdrawals were reported throughout the trial and stimulation was generally well-tolerated with three patients reporting headache. A methodological limitation is the lack of a control group and concurrent treatment with other psychotropic medications.

In a recent open-label trial, ${ }^{43} 10$ patients (five patients with OCD, three with Tourette's syndrome, and two with both) with a history of several medication trial failures were treated for 2 weeks with low-frequency TMS (10 sessions; frequency: $1 \mathrm{~Hz}$; intensity: $100 \%$ 1,200 stimuli/day; trains of 5 minutes with an inter-train interval of 2 minutes). All patients had been receiving pharmacologic treatment for at least 12 weeks at stable doses. Medications were continued at stable doses throughout the rTMS and the follow-up period. Of note, the supplementary motor area (SMA) was chosen as the site of stimulation with the coil placed along the sagittal midline in order to stimulate the SMA bilaterally and simultaneously. Eight out of 10 patients completed the study, and the treatment was well-tolerated with no dropouts due to side effects being reported. The sample had a significant general clinical improvement on the Clinical Global Impression Scale ${ }^{45}$ at the end of the first and second week of treatment, and maintained that benefit at 1 month $(t=5.670 ; d f=9 ; P=.000)$ and 3 month $(t=5.582 ; d f=9$; $P=.000)$ follow-up. Three of the five OCD-alone patients had a clinically significant improvement, with a $>40 \%$ reduction in Y-BOCS scores, and two thirds of the patients with Tourette's syndrome alone had a complete remission at the second week (total Yale Global Tic Severity Scale [YGTSS] ${ }^{46}$ scores of 0 from baseline scores of 90 and 70 , respectively). Sixty percent of the total sample had sustained clinical improvement with rTMS that persisted at the 3-month follow-up. Limitations of the study involve the open design and the small sample size. 


\section{Deep Brain Stimulation Studies in Obsessive- Compulsive Disorder}

The rationale for the use of DBS in OCD treatment is based on neuroimaging findings showing increased activity in specific neuronal circuits, such as the medial and orbitofrontal cortex, the anterior cingulate gyrus, and the caudate nucleus in these patients. ${ }^{47}$ Given that the blocking effect of high-frequency DBS on the stimulated area mimics the effect of tissue lesioning, ${ }^{26,27}$ DBS applied to specific areas (the anterior limbs of the internal capsula) would interrupt these hyperactive circuits in the same way as traditional neurosurgical procedures. However, DBS does not cause the irreversible ablation of brain

\section{TABLE 1. ECT EFFICACY IN OCD TREATMENT IN BLINDED AND NON-BLINDED STUDIES AND CASE- REPORT SERIES}

$\begin{array}{lll}\begin{array}{l}\text { Authors } \\ \text { (year) }\end{array} & \begin{array}{l}\text { Study } \\ \text { Design } \\ \text { \& Setting }\end{array} & \underline{\text { Sample Features }} \\ \begin{array}{l}\text { Maletzky } \\ \text { et al } \\ (1994)^{29}\end{array} & \begin{array}{l}\text { UB; UC; } \\ \text { Inpatients }\end{array} & \begin{array}{l}\text { 32 patients with DSM-II-R, treat- } \\ \text { ment-resistant OCD treated with }\end{array} \\ \begin{array}{l}\text { ECT between 1979 and 1991, 19 } \\ \text { non-depressed and 13 depressed; 14 } \\ \text { were primarily checkers, 13 were pri- } \\ \text { marily cleaners, 4 did both; Mean of } \\ \text { prior medication trials: 7 }\end{array}\end{array}$

$\begin{array}{lll}\begin{array}{l}\text { Thomas } \\ \text { et al } \\ (2003)^{30}\end{array} & \begin{array}{l}\text { UB; UC; } \\ \text { Inpatient }\end{array} & \begin{array}{l}\text { 1 patient with recurrent major } \\ \text { depression with psychotic features } \\ \text { and treatment-resistant OCD }\end{array} \\ \begin{array}{lll}\text { Lavin } \\ \text { et al }\end{array} & \begin{array}{l}\text { UB; UC; } \\ (199)^{31}\end{array} & \begin{array}{l}\text { 1 patient with schizophrenia and } \\ \text { treatment-resistant OCD }\end{array}\end{array}$

$(1996)^{31}$
Casey UB; UC; 1 elderly (84 years of age) woman
et al Inpatient with intractable depression and
$(1994)^{32}$ treatment-resistant OCD

\begin{tabular}{lll} 
Tx Group & $\begin{array}{c}\text { Control } \\
\text { Group }\end{array}$ & Trial Length \\
\hline Bilateral fronto- & & $\begin{array}{l}\text { Mean of } 3.5 \text { ses- } \\
\text { sions over } 2-3 \text { wks, } \\
\text { temporal ECT; }\end{array}$ \\
average 3-5 sei- & $\begin{array}{l}\text { evaluations } 2 \text { days } \\
\text { prior to start and } \\
\text { at } 5 \text { days and } 6 \text { and } \\
12 \text { months after the } \\
\text { end of treatment }\end{array}$ \\
&
\end{tabular}

One session of unilateral frontotemporal ECT; biweekly therapy sessions

Bilateral frontotemporal ECT; 12 sessions

\section{Not specified}
Bilateral frontotem- poral ECT; a 6-ses- sion trial, resumed after 5 months and 18 more sessions were completed within 1 year
1 year

\section{Bilateral fronto-} temporal ECT; 10 sessions

$$
\begin{aligned}
& 4 \text { weeks, 10-month } \\
& \text { follow-up }
\end{aligned}
$$

1 patient with treatment-resistant toms were reduced following a spontaneous seizure et al Inpatient

$(1984)^{33}$

\section{Strassnig UB; UC; et al Inpatient $(2004)^{34}$}

1 patient with treatment-resistant DSM-IV OCD and Tourette's syndrome, OC, and tic symptoms were resolved completely for 2 months following benzodiazepine withdrawal-induced seizures

\author{
Unilateral fron- \\ totemporal ECT \\ (right), 9 sessions \\ over 3 weeks, \\ monthly mainte- \\ nance sessions
}

$E C T=$ electroconvulsive therapy; $O C D=$ obsessive-compulsive disorder; TX=treatment; UB=unblinded; UC=uncontrolled; $D S M-I I I-R=D i a g n o s t i c$ and Statistical Manual of Mental Disorders, Third Edition-Revised; BHS=Bunney Hamburg Depression Scale; WT=Wakefield Depression Test; $\mathrm{M}-\mathrm{OCl}=$ Maudsley Obsessive-Compulsive Inventory; OC=obsessive-compulsive; CMI=clomipramine; DSM-III=Diagnostic and Statistical Manual of Mental Disorders, Third Edition; DSM-IV=Diagnostic and Statistical Manual of Mental Disorders, Fourth Edtion.

Dell'Osso B, Altamura AC, Allen A, Hollander E. CNS Spectr. Vol 10, No 12. 2005. 
tissue that is characteristic of neurosurgery.

To date, only a few small-sample, double-blind trials have been published on the efficacy of DBS in OCD. A group of Belgian researchers ${ }^{48}$. ${ }^{50}$ reported on six subjects with OCD refractory to various antiobsessional medications and cognitive-behavioral therapy (CBT) (Y-BOCS $>30$,
Global Assessment of Function [GAF] $<45$, both for a minimum of 5 years) who were treated with DBS. Quadripolar electrodes were implanted bilaterally in the anterior limbs of the internal capsules (parameters: pulse width of 210-450 microseconds, a frequency of $100 \mathrm{~Hz}$ and an amplitude range of 4.0-10.5 volts); the stimulator-off condition rep-

\section{Outcomes}

Comparison between the baseline scores (BHS, WT, M-OCI) with the scores from 5 days after yielded highly significant prepost paired $t$-test $(P<.001)$; at 6 -months posttreatment, the differences were still significant; by 12 months, only the M-OCI scores remained significantly different from those prior to ECT; 5 patients reported posttreatment agitation, which was treated with benzodiazepine

After one ECT session, the patient achieved remission of both conditions; venlafaxine $150 \mathrm{mg}$ /day was then resumed and improvement was maintained for 6 months; the patient reported transient fleeting confusion and a mild headache

After 12 sessions of ECT, the patient was improved and was started on paroxetine $20 \mathrm{mg} /$ day and haloperidol $7.5 \mathrm{mg} /$ day; evaluations at 6 months showed few checking thoughts and urges and a lessening of hoarding behavior

After 1 cycle of ECT the patient showed a dramatic clinical response which was longlasting for depression but temporary for OCD; maintenance ECT was effective for the OCD; this was stopped when CMI became available and patient responded adequately to drug; the patient reported transient post-ECT confusion that resolved within several days

Dramatic improvement of OC symptoms after 3 weeks and complete remission after the ninth ECT session; after the tenth session, the patient became slightly hypomanic and demonstrated increased energy and pressure speech but no psychosis and was therefore placed on lithium and nortryptiline as maintenance therapy; 10 months after ECT, the patient was still free of obsessions

Great improvement of OC symptoms and tics after 5 weeks of ECT treatment and complete remission of both conditions after the ninth ECT session; monthly maintenance ECT treatments were then scheduled and remission of both disorders has been maintained successfully for $>1$ year

\section{Conclusions}

Small retrospective study showing an anti-obsessional effect for ECT; the improvements occurred equally frequently and, to an equal extent, in depressed and non-depressed groups; besides not being blinded, methodological limitations are the absence of standard outcome measures, the use of other drugs during the long-term phase, and the presence of comorbid depression in a significant rate (13 of 32)

Single case-report showing the effectiveness of ECT over OC and depressive symptoms; there was no mention of evaluation scales for OCD; relevant Axis I comorbidity may have influenced the outcome

Single-case report showing the effectiveness of ECT over OC symptoms; there was no mention of evaluation scales; relevant Axis I comorbidity may have influenced the outcome; there was no mention of treatment-related side effects.

Single-case report showing the effectiveness of ECT over OC symptoms in an elderly patient; there was no mention of evaluation scales; relevant Axis I comorbidity may have influenced the outcome

Single-case report showing the effectiveness of ECT over OC symptoms; there was no mention of evaluation scales

Single-case report showing the effectiveness of ECT over OCD and Tourette's syndrome symptom; remission was maintained successfully with monthly ECT treatments; there was no mention of evaluation scales 
resented the placebo condition throughout the 21 months of evaluations. During all evaluation sessions, the patients and the evaluating psychiatrists and psychologists were blind to the stimulation condition. Four patients were assessed and treated in a blind crossover study (ie, stimulator on for 3 months with initial plans to follow this period with the stimulator off for 3 months, or vice versa, in random order, as determined by an independent person on the basis of a coin toss) and completed both arms of the crossover study. Evaluations were conducted over 21 months. Of the four completers, $75 \%$ were considered responders during the stimulation-on condition (response defined as postoperative Y-BOCS scores at least 35\% lower than the preoperative scores). For these four patients, mean CGI scores were 5 in the stimulation-off condition and 3.3 when the stimulator was turned on. Side effects included fatigue and memory disturbances. This small case series showed that bilateral electrical stimulation in the anterior limbs of the internal capsules may induce a significant decrease

\section{TABLE 2. TMS EFFICACY IN OCD TREATMENT IN BLINDED AND NON-BLINDED STUDIES AND CASE- REPORT SERIES}

\begin{tabular}{|c|c|c|}
\hline $\begin{array}{l}\text { Authors } \\
\text { (year) }\end{array}$ & $\begin{array}{l}\text { Study } \\
\text { Design } \\
\text { \& Setting } \\
\end{array}$ & $\underline{\text { Sample Features }}$ \\
\hline $\begin{array}{l}\text { Alonso } \\
\text { et al } \\
(2001)^{40}\end{array}$ & $\begin{array}{l}\text { DB; RA; } \\
\text { PC; } \\
\text { Outpatients }\end{array}$ & $\begin{array}{l}18 \text { patients with DSM-IV } \\
\text { OCD; No other DSM-IV } \\
\text { Axis I disorders; no dropouts }\end{array}$ \\
\hline $\begin{array}{l}\text { Sachdev } \\
\text { et al } \\
(2001)^{41}\end{array}$ & $\begin{array}{l}\text { SB; AC; } \\
\text { RA; } \\
\text { Outpatients }\end{array}$ & $\begin{array}{l}12 \text { patients with treatment- } \\
\text { resistant OCD, all of them } \\
\text { had received anti-obsessional } \\
\text { drugs in the past (mean: } 5.2 \\
\text { drugs); } 75 \% \text { had history of } \\
\text { depression; no dropouts }\end{array}$ \\
\hline $\begin{array}{l}\text { Greenberg } \\
\text { et al } \\
(1997)^{42}\end{array}$ & $\begin{array}{l}\text { AC; PC; } \\
\text { Outpatients }\end{array}$ & $\begin{array}{l}12 \text { patients with DSM-III- } \\
R \text { OCD; mean Y-BOCS } \\
19.8 \pm 9.7 ; 6 \text { patients met cri- } \\
\text { teria for past or current major } \\
\text { depression; no dropouts }\end{array}$ \\
\hline
\end{tabular}$$
\begin{array}{ll}
\text { Mantovani } & \text { UB; UC; } \\
\text { et al } & \text { Outpatients } \\
(2005)^{43} &
\end{array}
$$

10 patients with DSM-IV

OCD ( 5 patients with OCD,

3 with Tourette's syndrome and 2 with both the conditions) and history of several medication trial failure; patients continued SSRI at stable doses throughout the trial
10 sessions of real TMS, frequency: 10 $\mathrm{Hz} ; 30$ trains of $5 \mathrm{sec}-$ onds each, 25 seconds between train; time: 15 minunites; intensity: $110 \%$, right; 8-shaped coil

1 session of real TMS; frequency: $20 \mathrm{~Hz}, 2$ seconds/minute; time: 20 minutes; intensity: $80 \%$; 1 session in the right and 1 session in the left side; 8-shaped coil

\section{Active low-frequency} TMS on the supplementary motor area; frequency: $1 \mathrm{~Hz}$; intensity: $100 \% ; 1,200$ stimuli/day; trains of 5 minutes with intertrain interval of 2 minutes

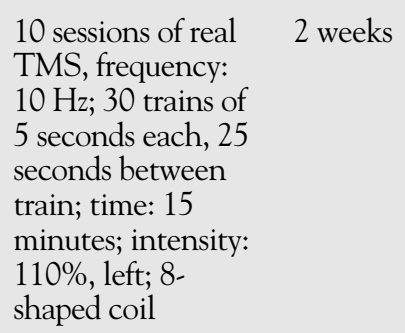

\section{2 weeks}

1 session of sham stimulation; frequency: $20 \mathrm{~Hz}, 2$ seconds/minute; time: 20 minutes; intensity: $80 \%$ in the midoccipital region; 8-shaped coil 2 weeks
Trial Length

6 weeks (3 sessions per week)
Evaluations made during the stimulation, 30 minutes and 8 hours after treatment

TMS=transcranial magnetic stimulation; $O C D=$ obsessive-compulsive disorder; Tx=treatment; $D B=d$ double-blind; $R A=r a n d o m$ assignment; DSM-IV=Diagnostic and Statistical Manual of Mental Disorders, Fourth Edition; PC=placebo-controlled; Y-BOCS=Yale-Brown Obsessive-Compulsive Scale; rTMS=repetetive transcranial magnetic stimulation; SB=single-blind; AC=active comparision; DSM-III-R=Diagnostic and Statistical Manual of Mental Disorders, Third Ediition-Revised; UB=unblinded; UC=uncontrolled; SSRI=selective serotonin reuptake inhibitor; YGTSS=Yale Global Tic Severity Scale.

Dell'Osso B, Altamura AC, Allen A, Hollander E. CNS Spectr. Vol 10, No 12. 2005. 
in OCD symptoms based on double-blind evaluations. Responders reported clinically meaningful improvement in the first week of stimulation. A dose-response effect with stimulation was found because the effect persisted for at least 21 months, suggesting that a placebo effect was unlikely. With regard to the other two patients, they completed the study afterwards and their results were published separately. Patient 5 received one electrode in each dorsomedial nucleus of the thalamus and one in each internal capsule. The study design was therefore different. The patient was always stimulated bilaterally in either the internal capsule or the dorsomedial nucleus. These conditions were then compared with the stimulation-off condition in a gradual-exposure experiment lasting 15 minutes. Each combination was tested twice in a randomized order. Final results showed that the dorsomedial nucleus did not seem to be a good target for this patient who, moreover, was considered a nonresponder with longer-term internal capsule stimulation. Patient 6 experienced a tremendous

\section{Outcomes}

Low-frequency right prefrontal TMS failed to produce significant improvement in OCD (Y-BOCS) or any difference from sham TMS; all patients completed the study; 1 patient receiving real TMS reported mild headache; no seizures, neurological complications, or reports of cognitive difficulties

Evaluations after 2 weeks of stimulation and 4 weeks after the treatment showed significant reduction in obsessions and compulsions in the 2 groups with no significant difference between right and left stimulation on the overall Y-BOCS score; 4 patients $(33 \%, 2$ left and 2 right) had a clinical significant improvement (Y-BOCS reduction $>40 \%$ ); 1 patient relapsed but responded somewhat to repeat treatment

Compulsive urges decreased significantly from baseline (NIMH modified) after right lateral prefrontal rTMS (during stimulation, 30 minutes, both $P<.01$, and 8 hours after stimulation, $P<.02$ ), but not after left rTMS and not at all in response to occipital rTMS; obsessive thoughts did not change significantly after stimulation; there was a modest increase in positive mood after right prefrontal rTMS, while left and occipital stimulation did not affect mood

The sample had a significant clinical general improvement at the end of the first and second week of treatment, and maintained benefit at 1-month and 3-months follow-up; 3 out of the 5 pure OCD patients had a clinically significant improvement, with a reduction in Y-BOCS scores $>40 \%$, and 2 of 3 of the patients with pure Tourette's syndrome had a complete remission at second week (total YGTSS scores of 0 from baseline scores of 90 and 70); $60 \%$ of the total sample had sustained clinical improvement with rTMS that persisted at 3-months follow-up

\section{Conclusions}

Small-size sample study showing no advantage for OCD patients treated with low-frequency right rTMS in comparison with patients treated with sham stimulation; negative findings may be related to type II error, since a minimum of 27 subjects in each treatment condition would have been necessary to reach an $80 \%$ power

rTMS may be beneficial in the acute treatment of treatment-resistant OCD patients with an equal proportion of patients benefiting from either rightor left-sided stimulation; stimulation was generally well-tolerated by subjects with 3 reporting headache; a methodological limitation is the lack of a controlled group

Small-size, blind-rater study showing that right prefrontal rTMS had modest acute effects on compulsions, whereas effects of left lateral prefrontal and occipital stimulation were transient and nonsignificant; obsessions seemed unaffected by rTMS. Treatment was well-tolerated with 2 patients reporting mild headache after stimulation; methodological limitations involved the duration of the treatment (one session) and lack of Y-BOCS outcome measures

Small-size open-label trial showing the efficacy of low-frequency rTMS in patients with OCD; a different target (the supplementary motor area) was chosen as stimulation target; no dropouts due to side effects were reported; treatment was welltolerated; limitations involved the design and the small sample 
improvement ( $>50 \%$ decrease in postoperative tests) in his aggressive, intrusive thoughts when stimulation was activated. His mood improved dramatically as well. However, since his obsessions returned with the former intensity 1 week after the crossover to blinded stimulation-off condition, the research team, blinded to the stimulation condition, decided to end this treatment.

Abelson and colleagues ${ }^{51}$ conducted a doubleblind trial on four subjects with OCD refractory to at least four anti-obsessional medications and CBT (Y-BOCS > 25; GAF <44). The patients, who had been on stable medication regimens for $\geq 6$ weeks before surgery and during the blinded phase of the study, received DBS with the implant of quadripolar stimulating electrodes, placed stereotactically in the anterior limb of each internal capsule (parameters: fixed frequency: $130 \mathrm{~Hz}$, pulse width: 210 microseconds, and amplitude range: $3.0-10.5$ volts); the stimulator-off condition was used as the control. The double-blind phase of the study consisted of four consecutive 3 -week periods (in an alternating on-off design), followed by an open phase in which stimulation, medication and CBT were adjusted to optimize response for $\leq 1$ year. During the doubleblind phase, patient 2 showed a $>35 \%$ Y-BOCS improvement with stimulators on for periods 2 and 3. Patient 3 showed a more moderate Y-BOCS improvement but also a placebo response. Patient 1 showed greater improvement in OCD and depression scores with stimulators on than with them off, but these effects were small and not clinically meaningful. Patient 4 showed no consistent and meaningful effects of stimulation during the blinded phase. During the open phase, two patients showed a $>35 \%$ Y-BOCS improvement. One subject showed mood elevation in response to stimulation. Orbitofrontal deactivation was seen in the positron emission tomography scans of the two patients who had a positive clinical response and not in those patients who had no response. Side effects, mostly transient and prominent only at high amplitudes and monopolar settings, included tingling, nausea, and diarrhea. This combined double-blind, openlabel, case-report series showed positive results for DBS in some patients with refractory OCD. Results seemed comparable with those achieved with ablative, anterior capsulotomy. Chronic stimulation produced impressive reductions in OCD symptom ratings and depression, although in one patient the remission from depression was not maintained. Beneficial effects varied in onset ranging from 3 weeks to 12 months.
In addition, three recent single-case reports ${ }^{52-54}$ of open DBS treatment, supported the efficacy of DBS in treatment-resistant patients with OCD. Generally, stimulation was prolonged for several months after surgery and positive results were maintained in the subsequent follow-up visits for up to 15 months. No serious adverse events were reported.

\section{Electroconvulsive Therapy Studies in Obsessive-Compulsive Disorder}

The published literature on the use of ECT in treatment-resistant patients with OCD includes a case series and several individual cases; understandably, none was double-blind treatment (Table 3 ). The case series was reported by Maletzky and colleagues. ${ }^{29}$ This is a retrospective study of 32 patients with Diagnostic and Statistical Manual of Mental Disorders, Third Edition-Revised, treatmentresistant OCD who received ECT between 1979 and 1991 (19 non-depressed and 13 depressed; 14 were primarily checkers, 13 primarily cleaners, 4 did both). They were treated with bilateral frontotemporal ECT (mean: 3-5 seizures over 23 weeks) and were evaluated 2 days prior to the start of treatment and at 5 days, 6 months, and 12 months after treatment. Five days after treatment, there were highly significant differences between the pre- and post-scores (paired $t$-tests; $P<.001$ ) on the Bunney Hamburg Depression Scale, ${ }^{55}$ Wakefield Depression Test, ${ }^{56}$ and Maudsley Obsessive Compulsive Inventory. ${ }^{57}$ At 6-months posttreatment, the differences were still significant, however, by 12 months only the M-OCI scores remained significantly different from those prior to ECT. Five patients reported posttreatment agitation which was treated with benzodiazepines. In this study, ECT had an anti-obsessional effect and the improvements occurred equally frequently and to an equal extent in depressed and non-depressed groups. However, there are several methodological limitations, including not being double-blind, the absence of standard outcome measures, the use of other drugs during the longterm phase, and the presence of comorbid depression in a significant proportion of patients (13 of 32). Furthermore, the technique used by the authors in terms of electrode placement and number of seizure per session is not consistent with the standard ECT procedure.

In addition, several single-case reports ${ }^{30-34}$ provided further evidence of the possible efficacy of ECT in treatment-resistant OCD. However, the unblinded design of these reports, the fre- 
quent comorbidity with other Axis I psychopathology (schizophrenia, depression, and Tourette's syndrome), and the different parameters of ECT used limit the confidence that can be placed in the findings.

\section{DISCUSSION}

To date, there have been only four studies of TMS in OCD. ${ }^{40-43}$ These trials were promising but inconclusive for several reasons. They differed in design in important ways: site of stimulation, parameters, and treatment duration. In addition, the samples were small and only one trial was double-blind. A uniform target area for stimulation, such as the left dorsolateral prefrontal cortex for major depression, has not been established; there are published reports of symptom reduction following stimulation in both right and left prefrontal cortex and the SMA. Therefore, the promising findings notwithstanding, conclusions about the possible efficacy of TMS in OCD are only speculative and need further research support. Of note, in these studies TMS demonstrated good tolerability with no dropouts and only temporary mild side effects. This might be due to the non-invasiveness of this technique in comparison with more invasive techniques (DBS, ECT, and neurosurgery). However, clinicians have to be prepared for the possibility of seizure, which represents the most severe adverse event occurring with rTMS. The occurrence of a seizure is a very rare event that may be more common at high frequencies. In order to avoid seizures, clinicians should monitor patients' motor threshold weekly and maintain stimulation parameters in the range of the published guidelines. ${ }^{58}$

Since the power of penetration of TMS in the brain is no deeper than $2 \mathrm{~cm}$, the main target of this procedure is the brain cortex. This point has raised skepticism about the possible efficacy of TMS in OCD, given the well-established involvement of subcortical circuits in this disorder. However, although TMS's penetration is limited to $2 \mathrm{~cm}$, studies combining TMS with functional neuroimaging have revealed effects of TMS that are distant from the site of stimulation. ${ }^{18,59,60}$ Furthermore, coils with a deeper power of penetration are being investigated for their potential clinical use. ${ }^{61}$

In summary, although no recommendations on the use of this technique can be given, the promising results, non-invasiveness of TMS and good tolerability support further research with this technique.

In addition to promising case reports, the efficacy of DBS in severe, treatment-resistant or pharma- cologically intractable OCD is supported by two small double-blind studies. In the assessment of DBS efficacy in treatment-resistant OCD patients, a comparison with traditional neurosurgery may be helpful. DBS, in fact, might be considered the most recent, least invasive and non-ablative neurosurgical procedure for OCD. Although neurosurgical treatments for psychiatric disorders have a long and controversial history, neurosurgery is today a minimally invasive and highly selective treatment that is performed for only a few patients with severe, treatment-refractory psychiatric conditions like OCD. ${ }^{62}$ Therefore, preliminary positive findings achieved with DBS should be compared with most recent and consistent published data of neurosurgery trials. Recent unblinded, prospective, and retrospective studies ${ }^{63-68}$ report approximately one third of the patients respond (improvement $>35 \%$ on the Y-BOCS) after undergoing one or more neurosurgical procedures, including anterior capsulotomy, cingulotomy, limbic leucotomy, gamma knife capsulotomy. In this perspective, based only on recent reports, neurosurgery is an effective alternative for treatment-resistant or pharmacologically intractable OCD patients. However, the irreversibility of the procedure create concern about the potential appearance of long-term adverse events, such as personality changes, in addition to short-term side effects related to the surgical procedure. In addition, the surgical procedure would leave approximately two thirds of the patients in their presurgical condition. According to preliminary reported data, DBS might show similar efficacy, but given the non-ablative nature of the procedure, it would offer advantages of reversibility and adjustability. Nevertheless, possible complications of DBS may occur due to the surgical procedure, the device and equipment, and the stimulation itself. Given that the surgical procedure causes a small amount of displaced tissue, consequent complications may consist of possible seizure, hemorrhage, and infection. Published data on DBS in movement disorders, ${ }^{69-73}$ however, indicate the incidence of these complications to be $1 \%$ to $3 \%$ for seizure, $1 \%$ to $5 \%$ for hemorrhage, and from $2 \%$ to $25 \%$ for infection. Complications related to the device range from $5 \%$ to $15 \%$ and include the fracture of leads, disconnection, lead movement and malfunction. ${ }^{69-73}$ In addition, in cases in which DBS is effective, battery depletion can result in reemergence of symptoms. Sometimes, moreover, the implantable neurostimulators, need to be replaced, an inconvenience occurring approximately every 10 months, requiring a new surgical intervention with 
the associated risks. ${ }^{74}$ Adverse effects due to stimulation are the most common, but they are fully reversible with changes in stimulation technique. Finally, Landau and Perlmutter ${ }^{75}$ reported marked affective changes in patients with movement disorders treated with DBS.

The long history of ECT in psychiatric disorders notwithstanding, published data on the use of this procedure in the treatment of OCD are quite scarce, and mostly limited to single-case reports. In addition, it is likely that negative casereports would not have been published. There are some interesting reports of efficacy of ECT treatment in patients with treatment-refractory OCD that showed only mild and temporary side effects (confusion and headache) and no serious adverse

\begin{tabular}{|c|c|c|c|c|c|}
\hline $\begin{array}{l}\text { Authors } \\
\text { (year) }\end{array}$ & $\begin{array}{l}\text { Study } \\
\text { Design } \\
\text { \& Setting }\end{array}$ & $\underline{\text { Sample Features }}$ & Tx Group & $\begin{array}{l}\text { Control } \\
\text { Group }\end{array}$ & Trial Length \\
\hline $\begin{array}{l}\text { Nuttin } \\
\text { et al } \\
(1999)^{58} \\
\text { Nuttin } \\
\text { et al } \\
(2003)^{59} \\
\text { Gabriels } \\
\text { et al } \\
(2003)^{50}\end{array}$ & $\begin{array}{l}\mathrm{DB} ; \mathrm{PC} ; \\
\text { Crossover; } \\
\text { Inpatients }\end{array}$ & $\begin{array}{l}6 \text { subjects with DSM- } \\
\text { IV OCD refractory } \\
\text { to various anti-obses- } \\
\text { sional treatments, and } \\
\text { CBT; Y-BOCS }>30 \text {, } \\
\text { GAF }<45 \text {, both for a } \\
\text { minimum of } 5 \text { years; } \\
\text { only } 4 \text { completed the } \\
\text { entire study }\end{array}$ & $\begin{array}{l}\text { Quadripolar electrodes bilater- } \\
\text { ally in the anterior limbs of the } \\
\text { internal capsules; parameters: } \\
\text { pulse width: } 210-450 \text { micro- } \\
\text { seconds; frequency: } 100 \mathrm{~Hz} \text {; } \\
\text { amplitude range: } 4.0-10.5 \text { volts }\end{array}$ & $\begin{array}{l}\text { Stimulator- } \\
\text { off condi- } \\
\text { tion }\end{array}$ & Up to 21 months \\
\hline $\begin{array}{l}\text { Abelson } \\
\text { et al } \\
(2005)^{51}\end{array}$ & $\begin{array}{l}\text { DB; PC; } \\
\text { Inpatients }\end{array}$ & $\begin{array}{l}4 \text { subjects with DSM- } \\
\text { IV OCD refractory to } \\
\text { at least } 4 \text { anti-obses- } \\
\text { sional medications and } \\
\text { CBT; Y-BOCS }>25 \text {; } \\
\text { GAF }<44\end{array}$ & $\begin{array}{l}\text { Quadripolar stimulating } \\
\text { electrodes were placed stereo- } \\
\text { taxically in the anterior limb of } \\
\text { each internal capsule; param- } \\
\text { eters: fixed frequency: } 130 \mathrm{~Hz} \text {; } \\
\text { pulse width: } 210 \text { microseconds; } \\
\text { amplitude range: } 3.0-10.5 \text { volts }\end{array}$ & $\begin{array}{l}\text { Stimulator- } \\
\text { off condi- } \\
\text { tion }\end{array}$ & $\begin{array}{l}\text { DB phase: } 4 \text { consec- } \\
\text { utive } 3 \text {-week periods } \\
\text { (on-off design) } \\
\text { followed by an open } \\
\text { phase in which } \\
\text { stimulation, medica- } \\
\text { tion, and CBT were } \\
\text { allowed to optimize } \\
\text { response up to } 1 \text { year }\end{array}$ \\
\hline $\begin{array}{l}\text { Aouizerate } \\
\text { et al } \\
(2004)^{52}\end{array}$ & UB; UC & $\begin{array}{l}1 \text { inpatient with DSM- } \\
\text { IV OCD refractory to } \\
\text { prior traditional anti- } \\
\text { obsessional medica- } \\
\text { tions and CBT }\end{array}$ & $\begin{array}{l}\text { Quadripolar electrodes bilater- } \\
\text { ally, } 2 \text { in the nucleus accum- } \\
\text { bens, and } 2 \text { in the ventral } \\
\text { caudate nucleus; parameters: } 4 \\
\text { volts; frequency: } 130 \mathrm{~Hz} \text {, pulse } \\
\text { duration: up to } 130 \text { microsec- } \\
\text { onds }\end{array}$ & & Up to 15 months \\
\hline $\begin{array}{l}\text { Anderson } \\
\text { et al } \\
(2003)^{43}\end{array}$ & UB; UC & $\begin{array}{l}1 \text { inpatient with DSM- } \\
\text { IV OCD refractory to } \\
\text { prior traditional anti- } \\
\text { obsessional medications } \\
\text { and CBT; baseline Y- } \\
\text { BOCS score: } 34\end{array}$ & $\begin{array}{l}\text { Electrodes bilaterally in the } \\
\text { anterior limbs of the internal } \\
\text { capsules; parameters: } 2 \text { volts; } \\
\text { frequency: } 100 \mathrm{~Hz} \text {; pulse width: } \\
210 \text { microseconds }\end{array}$ & & Up to 10 months \\
\hline $\begin{array}{l}\text { Fontaine } \\
\text { et al } \\
(2004)^{54}\end{array}$ & UB; UC & $\begin{array}{l}1 \text { inpatient with } \\
\text { treatment refractory } \\
\text { OCD and Parkinson's } \\
\text { disease, Y-BOCS } \\
\text { score: } 32\end{array}$ & $\begin{array}{l}\text { Electrodes bilaterally in the } \\
\text { subtalamic nucleus performed } \\
\text { to treat Parkinson's disease } \\
\text { motor disability; parameters: } \\
3.5 \text { volts right and } 1.3 \text { volts } \\
\text { left; frequency: } 185 \mathrm{~Hz} \text {; pulse } \\
\text { width: } 60 \text { microseconds }\end{array}$ & & 12 months \\
\hline \multicolumn{6}{|c|}{ 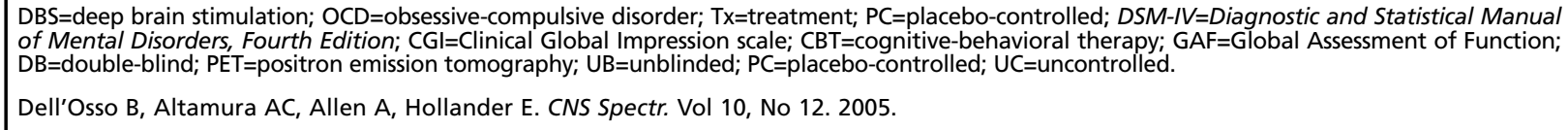 } \\
\hline
\end{tabular}


events. However, the frequent Axis I comorbidity, such as depression, among the study patients and the lack of standard outcome measures, keeps these studies from being considered definitive. When this weak evidence is considered along with the absence of blinded trials and the invasiveness of the procedure, it is clear that ECT cannot be strongly recommended for pure treat- ment-resistant OCD at this time. However, ECT could be used to target comorbid conditions, such as depression, that may be exacerbating OCD symptoms. Of note, multiple sclerosis, which has not yet been tested in OCD patients, might offer a more focal stimulation and a more benign sideeffect profile. Thus, this may be a valuable procedure to investigate further.

\section{Outcomes}

During the stimulation-on condition, 3 of the 4 patients were considered responders (postoperative Y-BOCS scores at least $35 \%$ lower than the preoperative scores) CGI scores decreased from 5 in the stimulation-off condition to a mean score of 3.3 for these 4 patients when the stimulator was turned on; side effects included fatigue and memory disturbances.

During the DB phase, 1 of 4 patients showed a $>35 \%$ Y-BOCS improvement; another patient showed a more moderate Y. BOCS improvement but also a placebo response and the other 2 patients did not show clinically significant response; during the open phase 2 patients showed a $>35 \%$ Y-BOCS improvement; 1 subject showed mood elevation in response to stimulation; orbitofrontal deactivation was seen in the PET scans of the 2 patients who had positive response and not in those patients who had no response; side effects, mostly transient and prominent only at high amplitudes and monopolar settings, included tingling, nausea, and diarrhea

After 12 months of treatment, DBS induced a major improvement in OCD symptoms (Y-BOCS <16) in addition to the reduction in the severity of depression and anxiety, which had occurred within the first 3 months post-DBS; neuropsychological testing showed no deterioration

Patient reported a dramatic improvement of symptoms; the 3-month postoperative Y-BOCS score was 7; at the 10-month follow-up, the patient was able to return to the workforce and all compulsions had abated

\section{Conclusions}

Small case-report series showing that bilateral electrical stimulation in the anterior limbs of the internal capsules may induce a significant decrease in OCD symptoms based on DB evaluations; responders reported clinically meaningful improvement in the first week of stimulation; the stimulation-induced beneficial effect was maintained for at least 21 months after surgery

Combined DB, open-label, case-report series showing positive results for DBS in some patients with refractory OCD. Results seemed comparable with those achieved with ablative, anterior capsulotomy; chronic stimulation produced impressive reductions in OCD symptom ratings and depression, although in 1 patient the depression remission was not maintained; beneficial effects needed variable time to appear ranging from 3 weeks to 12 months

Single-case report showing that DBS of the ventral caudate nucleus markedly reduced patient's OCD after 1 year of DBS; major depression was alleviated much earlier; no cognitive deterioration occurred and no side effects were reported

Single-case report showing a remarkable improvement of OCD symptoms after 10 months of DBS treatment; no adverse effects were reported

Single-case report showing a dramatic improvement in OCD symptoms in a patient with Parkinson's disease treated with DBS of the subtalamic nucleus 


\section{FUTURE DIRECTIONS}

TMS has already shown potential usefulness in at least three important domains-as a basic instrument for neuroscience research, as a potential clinical diagnostic tool, and as a therapy for various psychiatric disorders. However, TMS has been investigated only recently in the treatment of OCD and other anxiety disorders (ie, panic disorder, posttraumatic stress disorder), whereas a more consistent number of trials and related meta-analy$\operatorname{ses}^{76-80}$ have already reported greater antidepressant effects for rTMS in depressed patients. Doubts about the efficacy of TMS in OCD treatment have been raised by the limited depth of penetration of the technique $(\sim 2 \mathrm{~cm})$, given the involvement of subcortical circuits in the physiopathology of the disease, and by the absence of a well established localization for the stimulation. However, as already discussed, cortical stimulation does not exclude possible effects in distant and deeper areas. Additional clinical trials could help define the best position for the coil placement. Of note, this technique is the only one not requiring anesthesia: the patient is seated during the treatment, which is performed in day-hospital setting. Currently, TMS is the only brain stimulation device that can non-invasively and relatively painlessly focally stimulate the brain of awake individuals. ${ }^{81}$ Treatment-related side effects are mild and wel1-tolerated. Furthermore, it is easier to design and conduct double-blind clinical trails with TMS than with more invasive methods. In conclusion, the non-invasiveness, the good tolerability and the relative ease of conducting double-blinded trials represent important advantages for future research with TMS in OCD. Of note, the combination of TMS with functional neuroimaging in OCD trials might allow direct monitoring of TMS effects on the brain as already suggested by several studies. ${ }^{82}$

The efficacy of DBS in severe, treatment-resistant or pharmacologically intractable OCD has been tested so far in a small number of subjects. Published studies, some with a blinded design, have provided promising results. The rationale of DBS is to block hyperactive circuits of OCD with high frequency stimulating electrodes placed in the internal capsule. Certainly, this procedure is more invasive than TMS, it requires general anesthesia and entails risks related to the surgery, to the device and to the stimulation. In addition, it is important to highlight that eff ective stimulation parameters may vary notably across patients in terms of frequency and amplitude. However, when comparing DBS with traditional ablative neurosurgery, which is still controversial due to its irreversibility, DBS has the advantage of being reversible and nonablative nature. Further investigation of this technique is warranted

ECT is well established treatment for severe forms of depression; however, it showed mixed results in treatment-resistant OCD. Published cases reported on patients with high rates of comorbidity (ie, depression, schizophrenia) and, therefore, the validity of this procedure for pure OCD is unclear. Recent evolutions of ECT, such as MST, combining a more focal stimulation with better tolerability might produce renew interest in convulsive techniques in the treatment of OCD.

\section{CONCLUSION}

In the last decade, brain stimulation approaches to neuropsychiatric disorders have been increasingly investigated and are currently defining a "third way" of treatment besides the traditional ones, pharmacologic therapy and psychotherapy. Treatment-resistant OCD provides an important challenge for clinicians and researchers. For some of them, OCD can at times be an intractable illness. Nevertheless, there is a growing number of management options which open new prospects of treatment. Treatment studies with brain stimulation techniques (TMS, ECT, DBS) in severe, treatment-refractory or pharmacologically intractable OCD, have demonstrated different degrees of efficacy, which varies depending on the details of the technique, and different invasiveness and tolerability. Overall, there were important limitations in the design of the trials. Therefore, the level of confidence in the results of these therapies is limited, and none can be recommended at this time based on the published data. However, additional research is being conducted with TMS and DBS due to the promising findings and the non-invasiveness of the former procedure and the reversibility of the latter. Since these techniques can be studied in double-blind trials, it is possible that they may be refined and their efficacy and optimal treatment protocols may be established. CNS

\section{REFERENCES}

1. Karno M, Golding JM, Sorenson SB, Burnam MA. The epidemiology of obsessivecompulsive disorder in five U.S. communities. Arch Gen Psychiatry. 1988;45:10941099 .

2. Weissman MM, Bland RC, Canino JC, et al. The cross national epidemiology of obsessive compulsive disorder. The Cross National Collaborative Group. J Clin Psychiatry. 1994;55(suppl):5-10

3. Diagnostic and Statistical Manual of Mental Disorders. 4th ed. text rev. Washington, DC: American Psychiatric Association; 2000.

4. DuPont RL, Rice DP, Shiraki S, Rowland CR. Economic costs of obsessive-compulsive disorders. Med Interface. 1995;8:102-109. 
5. Kaplan A, Hollander E. A review of pharmacologic treatments for obsessivecompulsive disorder. Psychiatr Serv. 2003;54:1111-1118.

6. Goodman W, Price L, Rasmussen S, et al. The Yale-Brown Obsessive Compulsive Scale. I. Development, use, and reliability. Arch Gen Psychiatry. 1989;46:1006-1011.

7. Goodman W, Price L, Rasmussen S, et al. The Yale-Brown Obsessive Compulsive Scale. II. Validity. Arch Gen Psychiatry. 1989;46:1012-1016.

8. Pallanti S, Hollander E, Bienstock C, et al. Treatment non-response in OCD: methodological issues and operational definitions. Int J Neuropsychoph. 2002;5:181-191

9. Diering SL, Bell WO. Functional neurosurgery for psychiatric disorders: a historical perspective. Stereotact Funct Neurosurg. 1991;57:175-194.

10. Mashour GA, Walker EE, Martuza RL. Psychosurgery: past, present, and future. Brain Res Rev. 2005;48:409-419.

11. Lisanby SH, ed. Brain Stimulation in Psychiatric Treatment. Arlington, Va: American Psychiatric Publishing, Inc; 2004.

12. Bickford RG, Guidi M, Fortesque P, Swenson M. Magnetic stimulation of human peripheral nerve and brain: response enhancement by combined magnetoelectrical technique. Neurosurgery. 1987;20:110-116.

13. George MS, Lisanby SH, Sackeim HA. Transcranial magnetic stimulation: applications in neuropsychiatry. Arch Gen Psychiatry. 1999;56:300-311.

14. Schaepfer TE, Kosel M. Transcranial magnetic stimulation in depression. In: Lisanby SH, ed. Brain Stimulation in Psychiatric Treatment. Arlington, Va: American Psychiatric Publishing, Inc; 2004:1-22.

15. Pascual-Leone A, Valls-Sole J, Wassermann EM, Hallett M. Responses to rapid rate transcranial magnetic stimulation of the human motor cortex. Brain. 1994;117(pt 4):847-858.

16. Pascual-Leone A, Catala MD, Pascual Leone PA. Lateralized effect of rapid-rate transcranial magnetic stimulation of the prefrontal cortex on mood. Neurology. 1996;46:499-502.

17. Chen R, Classen J, Gerloff C, et al. Depression of motor cortex excitability by lowfrequency transcranial magnetic stimulation. Neurology. 1997;48:1398-1403.

18. Bohning DE, Shastry A, Wassermann EM, et al. BOLD-fMRI response to single-pulse transcranial magnetic stimulation (TMS). J Magn Reson Imaging. 2000;11:569-574

19. Catafau A, Perez V, Gironell A, et al. SPECT mapping of cerebral activity changes induced by repetitive transcranial magnetic stimulation in depressed patients. A pilot study. Psychiatry Res. 2001;106:151-160.

20. Schuurman PR, Bosch DA, Bossuyt PM, et al. A comparison of continuous thalamic stimulation and thalamotomy for suppression of severe tremor. N Engl J Med. 2000;342:461-468.

21. Deuschl G, Bain P. Deep brain stimulation for tremor [correction of trauma]: patient selection and evaluation. Mov Disord. 2002;17(suppl 3):S102-S111.

22. Tasker RR. Deep brain stimulation is preferable to thalamotomy for tremor suppression. Surg Neurol. 1998;49:145-153.

23. Pollack P, Fraix V, Krack P, et al. Treatment results: Parkinson's disease. Mov Disord. 2002;17(suppl 3):S75-S83.

24. Rezai AR, Mogilner AY, Cappell J, Hund M, Llinas RR, Kelly PJ. Integration of functional brain mapping in image-guided neurosurgery. Acta Neurochir Suppl. 1997;68:85-89.

25. Greenberg BD. Deep Brain Stimulation in Psychiatry. In: Lisanby SH, ed. Brain Stimulation in Psychiatric Treatment. Arlington, Va: American Psychiatric Publishing, Inc; 2004:53-65.

26. Bernabid AL, Pollack P, Gervason C, et al. Long-term suppression of tremor by chronic stimulation of ventral intermediate thalamic nucleus. Lancet. 1991;337:402-406.

27. Blond S, Caparros-Lefebvre D, Parker R, et al. Control of tremor and involuntary movement disorders by chronic stereotactic stimulation of the ventral intermediate thalamic nucleus. J Neurosurg. 1992;77:62-68.

28. American Psychiatric Association. The Practice of Electroconvulsive Therapy: Recommendations for Treatment, Training and Privileging. A Task Force Report of the American Psychiatric Association. 2nd ed Washington, DC: American Psychiatric Association; 2001.

29. Maletzky B, McFarland B, Burt A. Refractory obsessive compulsive disorder and ECT. Convuls Ther. 1994;10:34-42.

30. Thomas SG, Kellner CH. Remission of major depression and obsessiveCompulsive disorder after a single unilateral ECT. J ECT. 2003;19:50-51.

31. Lavin MR, Halligan P. ECT for obsessive-compulsive disorder and schizophrenia. Am J Psychiatry. 1996;153:1652-1653.

32. Casey DA, Davis MH. Obsessive-compulsive disorder responsive to electroconvulsive therapy in an elderly woman. South Med J. 1994;87:862-864

33. Mellman LA, Gorman JM. Successful treatment of obsessive-compulsive disorder with ECT. Am J Psychiatry. 1984;141:596-597.

34. Strassnig M, Riedel M, Muller N. Electroconvulsive therapy in a patient with
Tourette's syndrome and co-morbid obsessive compulsive disorder. World J Biol Psychiatry. 2004;5:164-166.

35. Tharyan P, Adams CE. Electroconvulsive therapy for schizophrenia. Cochrane Database Syst Rev. 2005;18:CD000076.

36. Rapoport M, Feder V, Sandor P. Response of major depression and Tourette's syndrome to ECT: a case report. Psychosom Med. 1998;60:528-529.

37. Husain SS, Kevan IM, Linnell R, Scott AI. Electroconvulsive therapy in depressive illness that has not responded to drug treatment. J Affect Disord. 2004;83:121-126.

38. Lisanby SH. Update on magnetic seizure therapy: a novel form of convulsive therapy. J ECT. 2002;18:182-188.

39. Sackeim HA. Magnetic stimulation therapy and ECT. Convuls Ther. 1994;10:255-258.

40. Alonso P, Pujol J, Cardoner N, et al. Right prefrontal repetitive transcranial magnetic stimulation in obsessive-compulsive disorder: a double-blind, placebocontrolled study. Am J Psychiatry. 2001;158:1143-1145.

41. Sachdev PS, McBride R, Loo CK, Mitchell PB, Malhi GS, Croker VM. Right versus left prefrontal transcranial magnetic stimulation for obsessive-compulsive disorder: a preliminary investigation. J Clin Psychiatry. 2001;62:981-984.

42. Greenberg BD, George MS, Martin JD, et al. Effect of prefrontal repetitive transcranial magnetic stimulation in obsessive-compulsive disorder: a preliminary study. Am J Psychiatry. 1997;154:867-869.

43. Mantovani A, Lisanby SH, Pieraccini F, et al. Repetitive transcranial magnetic stimulation (rTMS) in the treatment of obsessive-compulsive disorder (OCD) and Tourette's syndrome (TS). Int J Neuropsychoph. 2005 Jun 28;1-6 [Epub ahead of print].

44. Hoehn-Saric R, Benkefalt C. Structural and functional brain imaging in OCD. In: Hollander E, Zohar J, Marazziti D, ed. Current Concepts in OCD. New York, NY: Wiley; 1994:183-211.

45. Guy W, ed. ECDEU Assessment Manual for Psychopharmacology. Washington DC: US Department of Health, Education and Welfare; 1976:218-222. Publication ADM 76-338.

46. Leckman JF, Riddle MA, Hardin MT, et al. The Yale Global Tic Severity Scale: initial testing of a clinician-rated scale of tic severity. J Am Acad Child Adolesc Psychiatry. 1989;28:566-573.

47. Whiteside SP, Port JD, Abramowitz JS. A meta-analysis of functional neuroimaging in obsessive-compulsive disorder. Psychiatry Res. 2004;132:69-79.

48. Nuttin B, Cosyns P, Demeulemeester H, Gybels J, Meyerson B. Electrical stimulation in anterior limbs of internal capsules in patients with obsessive-compulsive disorders. Lancet. 1999;354:1526.

49. Nuttin BJ, Gabriels LA, Cosyns PR, et al. Long-term electrical capsular stimulation in patients with obsessive-compulsive disorder. Neurosurgery. 2003;52:1263-1274.

50. Gabriels L, Cosyns P, Nuttin B, Demeulemeester H, Gybels J. Deep brain stimulation for treatment refractory obsessive-compulsive disorder: psychopathological and psychopathological outcome in three cases. Acta Psychiatr Scand. 2003;107:275-282.

51. Abelson JL, Curtis GC, Sagher O, et al. Deep brain stimulation for refractory obsessive-compulsive disorder. Biol Psychiatry. 2005;57:510-516.

52. Aouizerate B, Cuny E, Martin-Guehl C, et al. Deep brain stimulation of the ventral caudate nucleus in the treatment of obsessive-compulsive disorder and major depression. Case report. J Neurosurg. 2004;101:682-686.

53. Anderson D, Ahmed A. Treatment of patients with intractable obsessive-compulsive disorder with anterior capsular stimulation. Case report. J Neurosurg. 2003;98:1104-1108.

54. Fontaine D, Mattei V, Borg M, et al. Effect of subthalamic nucleus stimulation on obsessive-compulsive disorder in a patient with Parkinson disease. Case report. J Neurosurg. 2004;100:1084-1086.

55. Bunney WE, Hamburg DR. Methods for reliable longitudinal observation of behavior. Arch Gen Psychiatry. 1972;9:280-287.

56. Snaith RP, Ahmed SM, Mehta S, Hamilton M. Assessment of the severity of primary depressive illness. Wakefield self-assessment depression inventory. Psychol Med. 1971;1:143-149.

57. Marks IM, Hallam RS, Phellepot R, et al. Nursing in Behavioral Psychotherapy. Research Series of the Royal College of Nursing. London, UK: Royal College of Nursing; 1977.

58. Wasserman EM. Risk and safety of repetitive transcranial magnetic stimulation: report and suggested guidelines from the International Workshop on the Safety of Repetitive Transcranial Magnetic Stimulation, June 5-7, 1996. Electroencephalogr Clin Neurophysiol. 1998;108:1-16.

59. Bohning DE, Pecheny AP, Epstein CM, et al. Mapping transcranial magnetic stimulation (TMS) in vivo with MRI. Neuroreport. 1997;8:2535-2538.

60. Paus T, Jech R, Thompson CJ, Comeau R, Peters T, Evans AC. Transcranial magnetic stimulation during positron emission tomography: a new method for studying connectivity of the human cerebral cortex. J Neurosci. 1997;17:3178-3184.

(Cont. on page 983) 